\title{
Climatic variability in Princess Elizabeth Land (East Antarctica) over the last 350 years
}

\author{
Alexey A. Ekaykin ${ }^{1,2}$, Diana O. Vladimirova ${ }^{1,2, a}$, Vladimir Y. Lipenkov ${ }^{1}$, and Valérie Masson-Delmotte ${ }^{3}$ \\ ${ }^{1}$ Climate and Environmental Research Laboratory, Arctic and Antarctic Research Institute, St Petersburg, Russia \\ ${ }^{2}$ Institute of Earth Sciences, Saint Petersburg State University, St Petersburg, Russia \\ ${ }^{3}$ Laboratoire des Sciences du Climat et de l'Environnement - IPSL, UMR 8212, CEA-CNRS-UVSQ-Université Paris Saclay, \\ Gif-sur-Yvette, France \\ anow at: Center for Ice and Climate, Niels Bohr Institute, University of Copenhagen, Juliane Maries Vej 30, \\ 2100 Copenhagen $\varnothing$, Denmark
}

Correspondence to: Alexey A. Ekaykin (ekaykin@aari.ru)

Received: 2 July 2016 - Published in Clim. Past Discuss.: 8 July 2016

Revised: 2 December 2016 - Accepted: 20 December 2016 - Published: 16 January 2017

\begin{abstract}
We use isotopic composition $(\delta \mathrm{D})$ data from six sites in Princess Elizabeth Land (PEL) in order to reconstruct air temperature variability in this sector of East Antarctica over the last 350 years. First, we use the present-day instrumental mean annual surface air temperature data to demonstrate that the studied region (between Russia's Progress, Vostok and Mirny research stations) is characterized by uniform temperature variability. We thus construct a stacked record of the temperature anomaly for the whole sector for the period of 1958-2015. A comparison of this series with the Southern Hemisphere climatic indices shows that the short-term inter-annual temperature variability is primarily governed by the Antarctic Oscillation (AAO) and Interdecadal Pacific Oscillation (IPO) modes of atmospheric variability. However, the low-frequency temperature variability (with period $>27$ years) is mainly related to the anomalies of the Indian Ocean Dipole (IOD) mode. We then construct a stacked record of $\delta \mathrm{D}$ for the PEL for the period of 1654-2009 from individual normalized and filtered isotopic records obtained at six different sites ("PEL2016" stacked record). We use a linear regression of this record and the stacked PEL temperature record (with an apparent slope of $9 \pm 5.4 \%{ }^{\circ} \mathrm{C}^{-1}$ ) to convert PEL2016 into a temperature scale. Analysis of PEL2016 shows a $1 \pm 0.6^{\circ} \mathrm{C}$ warming in this region over the last 3 centuries, with a particularly cold period from the mid-18th to the mid-19th century. A peak of cooling occurred in the $1840 \mathrm{~s}$ - a feature previously observed in other Antarctic records. We reveal that PEL2016 corre-
\end{abstract}

lates with a low-frequency component of IOD and suggest that the IOD mode influences the Antarctic climate by modulating the activity of cyclones that bring heat and moisture to Antarctica. We also compare PEL2016 with other Antarctic stacked isotopic records. This work is a contribution to the PAGES (Past Global Changes) and IPICS (International Partnerships in Ice Core Sciences) Antarctica 2k projects.

\section{Introduction}

While understanding the behaviour of the Antarctic climate system is crucial in the context of present-day global environmental changes, key gaps arise from limited observations. Prior to the International Geophysical Year (19551957), the primary sources of climatic data were ice core records. Deep ice cores have provided a wealth of climatic and environmental information covering glacial-interglacial variations of the past 800000 years (EPICA, 2004). However, the spatio-temporal characteristics of Antarctic climate variability in the most recent centuries remains poorly known and understood (Jones et al., 2016; PAGES 2k Consortium, 2013).

The network of ice core records spanning the last centuries is distributed highly unevenly. Quite extensive coverage of some regions of Antarctica, such as West Antarctica (Kaspari et al., 2004) or Dronning Maud Land (Altnau et al., 2015; Oerter et al., 2000) contrasts with other regions that re- 


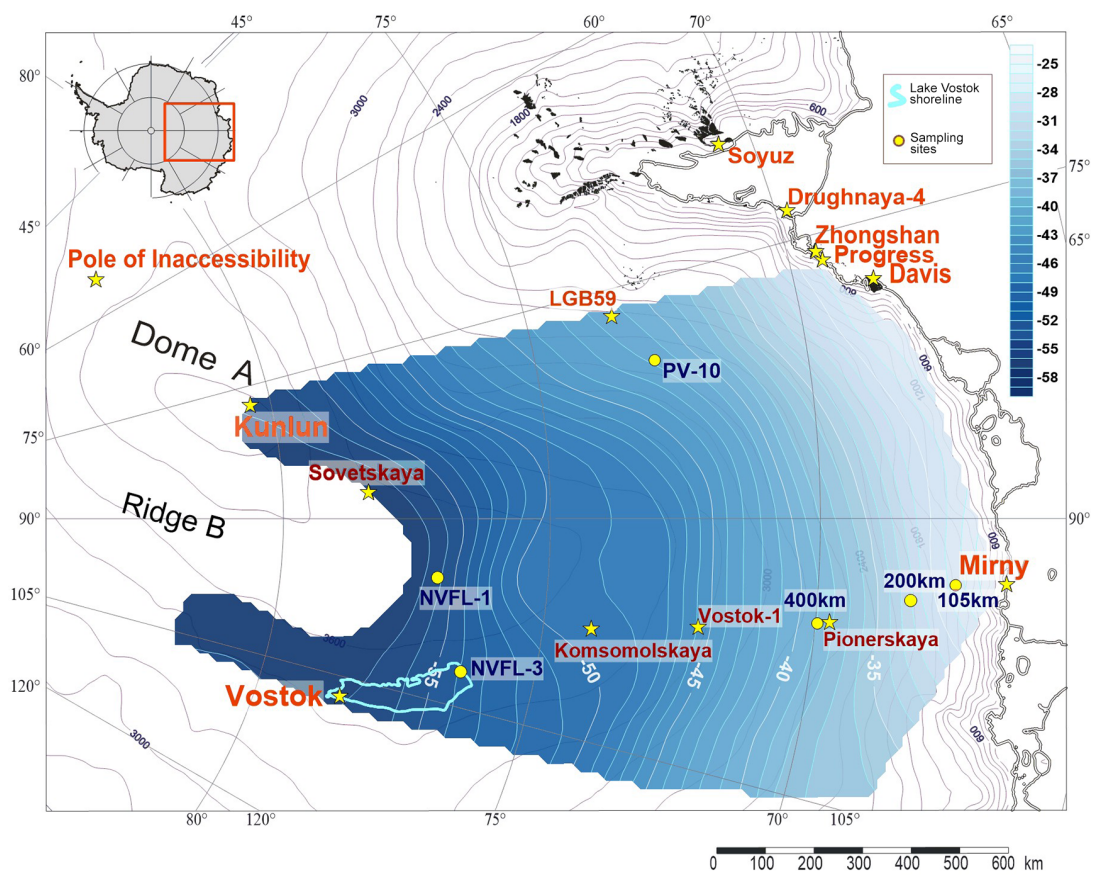

Figure 1. The Princess Elizabeth Land sector of East Antarctica. Blue iso-contours display the spatial pattern of surface snow $\delta^{18} \mathrm{O}$ (Vladimirova et al., 2017). The light blue contour shows the shoreline of subglacial Lake Vostok. Yellow dots mark the location of individual records used here. Stars depict the location of former or present research stations.

main poorly studied. As a result, attempts to reconstruct the climatic variability of the whole Antarctic continent (Jones et al., 2016; PAGES 2k Consortium, 2013; Schneider et al., 2006; Frezzotti et al., 2013) are limited by the lack of available data.

In our previous work we summarized available isotopic data for the vicinity of Vostok Station in order to construct a robust stack climatic record over the past 350 years (Ekaykin et al., 2014). Here we present a new stacked climate record for Princess Elizabeth Land (PEL), the territory located between the Russian stations of Progress, Vostok and Mirny, East Antarctica. This record is based on water stable isotope data from six sites and spans the last 350 years (Fig. 1). We note an imperfect correlation between the stacked isotopic record and regional surface air temperature variations, underlying the fact that the isotopic content of precipitation is not simply a proxy of temperature but rather a parameter that covaries with the local climate in a manner similar to temperature (Steig et al., 2013).

We also highlight significant relationships between regional climate and large-scale modes of variability of the Southern Hemisphere.

Section 2 describes our data and methods. Section 3 is focused on the results and their discussion before we conclude in Sect. 4.

\section{Methods}

\subsection{Ice core data}

In this study we use data from six individual records obtained in Princess Elizabeth Land (Fig. 1, Table 1).

The designation " $105 \mathrm{~km}$ " $\left(67.433^{\circ} \mathrm{S}\right.$ and $93.383^{\circ} \mathrm{E}$, time interval 1757-1987) refers to a $727 \mathrm{~m}$ ice core drilled in 1988 about $105 \mathrm{~km}$ inland from Mirny Station by specialists from the St Petersburg Mining Institute. The isotopic content was measured in the late 1980s at the Laboratoire des Sciences du Climat et de l'Environnement (LSCE) with a resolution of $1 \mathrm{~m}$. In 2013, the upper $109 \mathrm{~m}$ of the core were remeasured at the Climate and Environmental Research Laboratory (CERL), with a depth resolution of $5 \mathrm{~cm}$. This core is the only one in which the accumulation rate allows the annual layers to be preserved in the snow thickness, so the core was dated by layer counting. The initial dating was then adjusted using the reference horizon of the 1816 Tambora volcanic eruption, identified from electrical conductivity measurements (ECMs) (Vladimirova and Ekaykin, 2014). As a result, a record of the annual accumulation rate is available.

The designation " $400 \mathrm{~km}$ " $\left(69.95^{\circ} \mathrm{S}\right.$ and $95.617^{\circ} \mathrm{E}, 1254$ 1987) refers to an ice core drilled in 1988 at the 400th kilometre from Mirny Station, down to $150 \mathrm{~m}$ depth. Isotopic measurements were performed at LSCE on $1 \mathrm{~m}$ samples. The core was dated according to the simple Nye depth-age model, taking into account the average accumulation rate at the drilling site (Lipenkov et al., 1998) and the density profile 


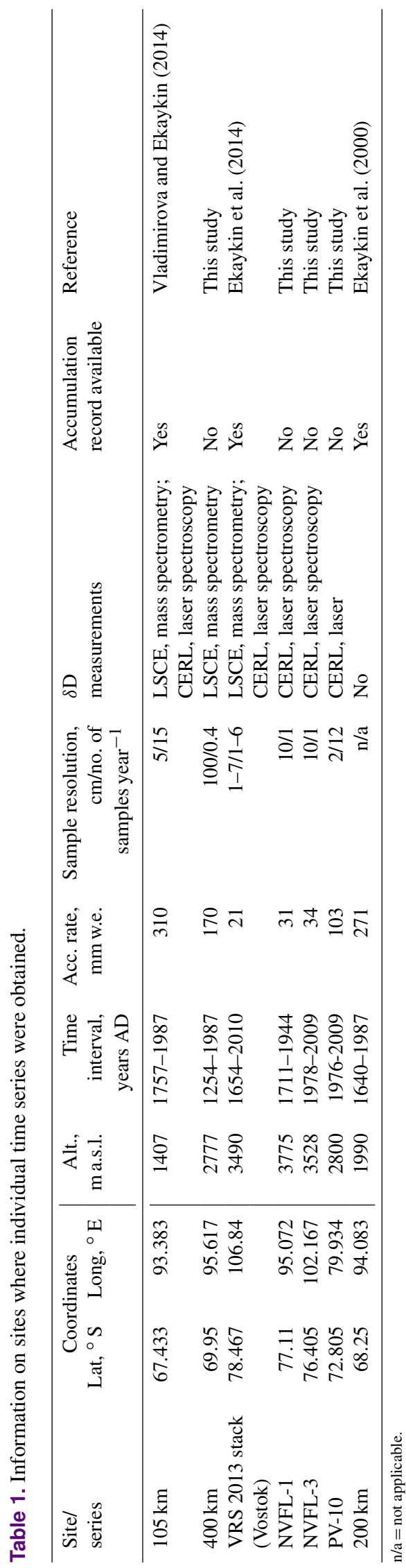

of the core. The uncertainty of the dating, estimated with the Nye model, mainly comes from the error of the accumulation rate estimate and is evaluated at about $10 \%$. As a result, no record of the annual accumulation rate is available.

The designation "VRS $2013^{\prime \prime}\left(78.467^{\circ} \mathrm{S}\right.$ and $106.84^{\circ} \mathrm{E}$, 1654-2010) refers to a stack of 15 individual isotopic records from snow pits and shallow cores recovered in the vicinity of Vostok Station (Ekaykin et al., 2014). The data on temporal variability of snow accumulation rate is also available for this site.

The designation "NVFL-1" $\left(77.11^{\circ} \mathrm{S}\right.$ and $95.072^{\circ} \mathrm{E}$, 1711-1944) refers to an $18.3 \mathrm{~m}$ firn core drilled from the bottom of a $2.5 \mathrm{~m}$ snow pit in 2008 close to Dome B. The chronology was established using the firn density data and the 1816 Tambora volcano ECM peak as a reference horizon.

The designation "NVFL-3" (76.405 $\mathrm{S}$ and $102.167^{\circ} \mathrm{E}$, 1978-2009) refers to a $3.1 \mathrm{~m}$ snow pit dug in 2010 in the northern part of subglacial Lake Vostok. It is dated based on snow stratigraphy and identification of the 1993 Pinatubo volcano peak in $\mathrm{SO}_{4}^{2-}$ vertical profile. Chemical measurements were performed at the Limnological Institute of the Russian Academy of Sciences, Irkutsk, Russia.

The designation "PV-10" $\left(72.805^{\circ} \mathrm{S}\right.$ and $79.934^{\circ} \mathrm{E}, 1976$ 2009) refers to a $7.55 \mathrm{~m}$ firn core drilled in 2010 about $400 \mathrm{~km}$ inland from Progress Station. It was dated using firn density data and takes into account the ECM peak associated with the 1993 deposition from the Pinatubo eruption.

We estimated the dating uncertainty by comparing age calculated using only firn density data and average snow accumulation rate for a given site with the age of the reference age markers and came to the conclusion that the age errors do not exceed $10 \%$. For the reference years (1816 and 1993, where we have absolute dating), the error approaches 0 . The largest error is expected for the $400 \mathrm{~km}$ series, where we do not have reference age markers. However, if we use the prominent 1840 cold event (see Sect. 3.3) observed in all records as a marker, then we may estimate a relative dating error for this series as $<6 \%$.

We also use the accumulation data from the site " $200 \mathrm{~km}$ " (Fig. 1), spanning the period 1640-1987, as published in Ekaykin et al. (2000). The accumulation values from sites " $150 \mathrm{~km}$ " and $400 \mathrm{~km}$ are corrected both for layer thinning with depth and for the advection of ice from upstream of the glacier to account for the spatial gradient of the snow accumulation rate.

\subsection{Stacked records}

Figure 2 displays the individual $\delta \mathrm{D}$ time series from all six sites. Differences between mean values reflect well-known differences in isotopic distillation along a gradient of inland elevation (e.g. Masson-Delmotte et al., 2008). In order to investigate temporal variations only, we calculate normalized values for each series using the interval 1757-1944 as a ref- 


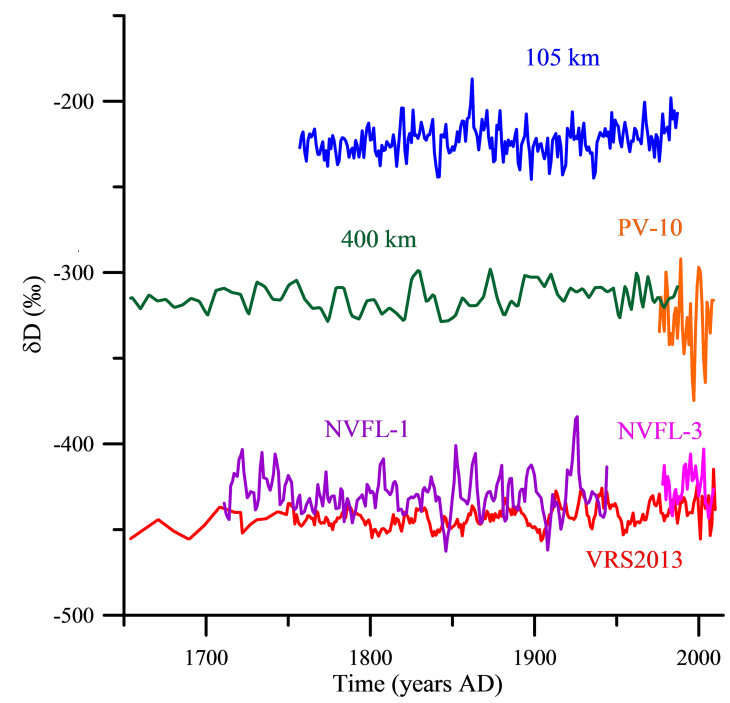

Figure 2. $\delta \mathrm{D}$ records from six individual series used in this study.

erence period. The short series (NVFL-3 and PV-10) are normalized over the 1978-2009 period, and then the mean and variance of the normalized values are adjusted to those of the long series for the corresponding period of time, in order to avoid an overestimated contribution of the short records in the stacked series.

We then apply a rectangular-shaped low-pass filter to cut off the variability with periodicities shorter than 27 years (i.e. frequencies $>0.037$ ). (All spectral analyses and filtering are performed with the use of Analyseries software; Paillard et al., 1996.) We decide to do this because one single record in inland Antarctica cannot provide reliable climatic information on a short-term timescale, due to a very low signal-tonose ratio (Ekaykin et al., 2014) and non-temperature effects on isotopes in precipitation including post-depositional alterations. Moreover, the latter study (Ekaykin et al., 2014) also highlighted multi-decadal climatic variability in this sector of central Antarctica, with a period of 30-50 years.

The normalized and filtered time series are displayed in Fig. 3. Despite some common features, this comparison shows significant discrepancies between individual records. One reason for the mismatches may lie in age scale uncertainties. However, this hypothesis is ruled out by the comparison of individual series around 1816 and 1993 (the dates of firn layers containing Tambora and Pinatubo volcanic eruption debris, denoted by vertical dashed lines in Fig. 3), when the relative dating error tends to 0 : observed discrepancies do not arise from chronological uncertainties alone. Alternatively, this mismatch may arise from a significant level of noise even in the filtered series and factors other than the local temperature that control the isotopic composition of precipitation.

In order to isolate the climatic signal from the noise, we constructed a stacked climatic record for the PEL region,

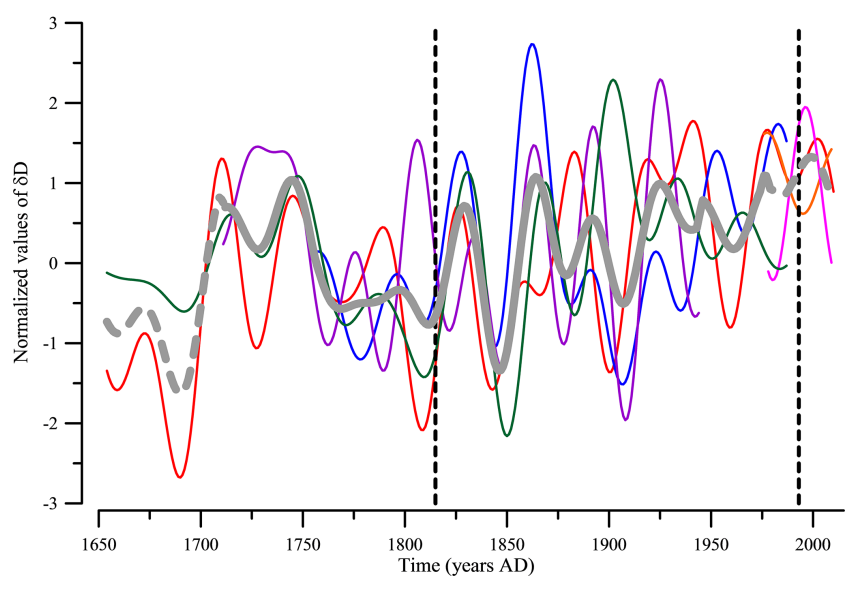

Figure 3. Normalized and low-pass-filtered individual records (with a cut-off for variations on timescales shorter than 27 years), displayed using the same colors as in Fig. 2. The thick grey line is the stacked record (PEL2016). The dashed grey lines show the less robust marginal parts of the stack. Vertical dashed lines mark reference horizons that contain the debris of Tambora (1815) and Pinatubo (1991) volcanic eruptions, respectively deposited until 1816 and 1993 in Antarctica.

hereafter named PEL2016 (grey line in Fig. 3). For a given year, the value of this record consists of the average of the values of individual records available for this year.

\subsection{Instrumental temperature data}

A number of research stations have been established in the PEL area, as indicated in Fig. 1. Unfortunately, most of them have very short (if any) meteorological records. Relatively long records are available only for five stations: the Australian station Davis (1957-1964 and 1969-2015), the Chinese station Zhongshan (1989-2015), and the Russian stations Progress (1989, 1991 and 2003-2015), Mirny (19562015) and Vostok (1958-2015 with gaps in 1962, 1994, 1996 and 2003). The monthly data were downloaded from https://legacy.bas.ac.uk/met/READER/ (Turner et al., 2004), and then the annual means were calculated.

The correlation between Progress, Zhongshan and Davis annual mean temperature datasets, located very close to each other, is $0.96-0.98$ (note that only statistically significant correlation coefficients with a confidence level $>95 \%$ are reported in the paper, unless otherwise mentioned). Hereafter, we only use data from the station with the longest record (Davis).

We also use data from the automatic weather station (AWS) LGB59 located at the slope of the Antarctic ice sheet inland from Progress Station (Fig. 1), available for the period 1994-1999, as well as surface air temperature data from Casey and Mawson. 


\subsection{Climatic indices of the Southern Hemisphere}

In order to investigate possible relationships between PEL climate multi-decadal variations and large-scale modes of variability, we use data on the indices of the Antarctic Oscillation (AAO), the Interdecadal Pacific Oscillation (IPO) and the Indian Ocean Dipole (IOD).

The AAO index, also known as the SAM (Southern Annular Mode), is defined as a mean latitudinal difference of sea level pressure at 40 and $65^{\circ} \mathrm{S}$ and is considered as a prevailing mode of atmospheric circulation in the Southern Hemisphere (SH) representing about $35 \%$ of the extratropical SH climate variability (Marshall, 2003). The monthly AAO index is available from NOAA (http: //www.cpc.ncep.noaa.gov/products/precip/CWlink/daily_ ao_index/aao/monthly.aao.index.b79.current.ascii.table; since 1979) and the British Antarctic Survey (http://www.antarctica.ac.uk/met/gjma/sam.html; since 1957, although data for the 1957-1978 period is considered to be less robust).

IPO is defined as a sea surface temperature (SST) anomaly over the Pacific Ocean. The positive phase of IPO is characterized by a relatively warm central and eastern tropical Pacific and a relatively cold north-western and southwestern Pacific (Henley et al., 2015; Dong and Dai, 2015). The IPO index is closely related to PDO (Pacific Decadal Oscillation), but PDO better characterizes the Northern Pacific, while IPO is better applicable to the whole Pacific region. We used IPO data because in the previous study we found a teleconnection between the climate variability in the central Antarctic and the tropical Pacific (Ekaykin et al., 2014). The data on the IPO index since 1870 are available here: http://www.esrl.noaa.gov/psd/data/timeseries/IPOTPI/.

The IOD is characterized by the Dipole Mode index (DMI), which is defined as the SST gradient between the western equatorial Indian Ocean $\left(50-70^{\circ} \mathrm{E}\right.$ and $\left.10^{\circ} \mathrm{S}-10^{\circ} \mathrm{N}\right)$ and the south-eastern equatorial Indian Ocean $\left(90-110^{\circ} \mathrm{E}\right.$ and $10^{\circ} \mathrm{S}-0^{\circ} \mathrm{N}$ ). Thus, IOD is an analogue of SOI (Southern Oscillation index), but for the Indian Ocean. The data on the DMI index since 1870 can be found at http://www.jamstec. go.jp/frsgc/research/d1/iod/iod/dipole_mode_index.html.

\section{Results and discussion}

\subsection{Surface air temperature variability in the Princess Elizabeth Land during the period of instrumental observations (1958-2015)}

Here, we first consider the variability of surface air temperature recorded at the meteorological stations in Princess Elizabeth Land to assess whether the studied sector is characterized by uniform climate variability and to provide a reference regional temperature record for comparison with the $\delta \mathrm{D}$ stacked record.
Table 2. Correlation matrix between individual surface air temperature records from meteorological stations in the Princess Elizabeth Land.

\begin{tabular}{lrrrrr}
\hline & Casey & Mirny & Davis & Mawson & Vostok \\
\hline Casey & 1 & 0.82 & 0.60 & 0.53 & 0.54 \\
Mirny & & 1 & 0.86 & 0.77 & 0.67 \\
Davis & & & 1 & 0.86 & 0.58 \\
Mawson & & & & 1 & 0.62 \\
Vostok & & & & & 1 \\
\hline
\end{tabular}

All the correlation coefficients are statistically significant with $95 \%$ confidence level.

Correlation coefficients between annual mean surface air temperature data at Vostok, Mirny and Davis vary between 0.6 and 0.9 (Table 2). Correlation coefficients between the automatic weather station LGB59 (located between Davis and Vostok, Fig. 1) and these three stations vary between 0.86 and 0.96. Despite the short record at LGB59, they are also significant at the $95 \%$ confidence level. These results demonstrate that the region encompassed between these three stations has experienced similar climatic variability. This is further confirmed by a cluster analysis of surface air temperature data from 12 Antarctic stations (see Fig. S1 in the Supplement), showing that Vostok, Mirny, Casey, Mawson and Davis data form a single cluster in terms of climatic variability.

Interestingly, the correlation coefficient between Mirny and Vostok data is significantly weaker in 1958-1976 $(R=$ $0.53)$ than in $1976-2015(R=0.74)$. This suggests that, before the so-called "1976 climate shift" (Giese et al., 2002) Vostok experienced a higher influence from the Pacific sector of the Southern Ocean (Ekaykin et al., 2014) not encompassed at Mirny. Indeed, the correlation coefficient between temperature data from Vostok and McMurdo Station (located in the Pacific sector) was higher before the 1976 shift $(R=0.46)$ than after $1976(R=0.35)$.

During the whole period of instrumental observations, the strongest relationships observed for temperature at Vostok were with temperature data at Mirny and Mawson coastal stations from the Indian Ocean sector and more precisely the sector between the Davis Sea and the Cooperation Sea.

As a result, Fig. 4a shows the average temperature anomaly from Vostok, Mirny and Davis stations. Hereafter, we use this stacked temperature record as an estimate of the temperature anomaly for the whole PEL sector.

We then compare the low-frequency variations in these various temperature records, using the 27-year low-pass filter (Fig. S2). Both Vostok and Mirny demonstrate a quasiperiodical variability with a period of about 30 years and maxima in the late 1970 s and the late 2000s and demonstrate a very high similarity at low frequency. While Davis data have the same periodicity, their maxima are shifted to the early $1970 \mathrm{~s}$ and early 2000s. If we consider other Antarctic stations, we 

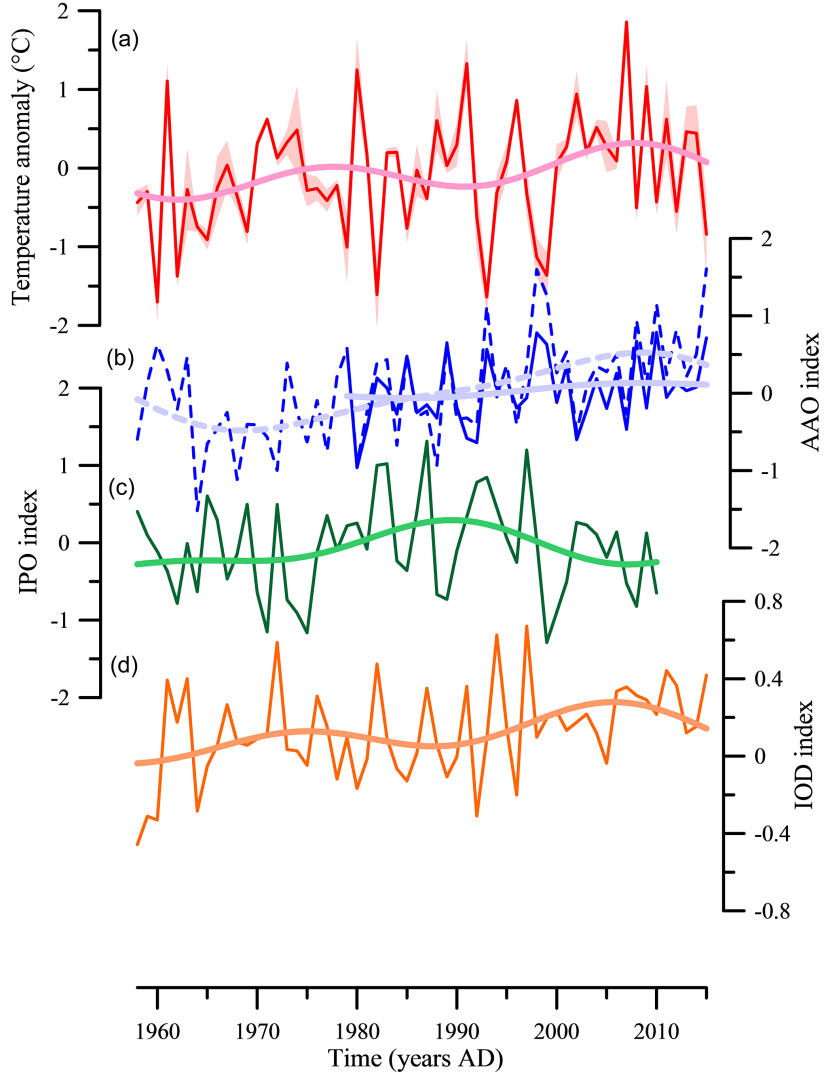

Figure 4. Climatic variability in the Southern Hemisphere in 19582015. (a) Composite temperature anomaly in the Princess Elizabeth Land (based on records from Mirny, Davis and Vostok). The red shading displays \pm 1 standard error of mean. (b) Antarctic Oscillation index from NOAA (solid line) and BAS (British Antarctic Survey) (dashed line). See text for details. (c) Interdecadal Pacific Oscillation index. (d) Indian Ocean Dipole index. Thick lines are low-pass filtered (with a cut-off for variations on timescales shorter than $<27$ years).

see complex behaviour of air temperature in different sectors of Antarctica: most stations also show a 30-year cycle, but with a significant phase shift relative to the PEL region.

In the Indian Ocean sector, temperature peaks appear increasingly delayed when moving from west to east. For example, the first maximum occurred late in the 1960s at Mawson, early in the 1970s at Davis, in the second half of the 1970s at Mirny and late in the 1970s at Casey. This feature may reflect a low-frequency component of the Antarctic Circumpolar Wave (Carril and Navarra, 2001).

With respect to multi-decadal trends, contrasted patterns emerge: some stations (Esperanza, Novolazarevskaya, Davis, Vostok, Mirny, McMurdo) display a warming trend, while a cooling trend emerges at Halley or Dumont d'Urville (Fig. S2).

This comparison of instrumental temperature records highlights different patterns of multi-decadal variability across different sectors of Antarctica, which is important for interpreting paleoclimate records and for combining various proxy records for temperature reconstructions (Jones et al., 2016). Our analysis nevertheless demonstrates coherency within Princess Elizabeth Land, where we will use the stacked temperature record from Vostok, Mirny and Davis as a reference regional signal (hereafter named PEL temperature anomaly) for the calibration of $\delta \mathrm{D}$ records.

\subsection{Relationships between Princess Elizabeth Land instrumental temperature records and Southern Hemisphere modes of variability}

Here we compare the PEL temperature anomaly with indices that characterize climatic variability in the Southern Hemisphere. First, as expected, a very strong negative relationship with the AAO index $(r=-0.68)$ is observed in 19792015 (Fig. 4b). The Antarctic Oscillation is the predominant mode of climatic variability in Antarctica: a strong AAO index reflects a larger pressure gradient between low and high latitudes, associated with a more zonal circulation around Antarctica and colder conditions in East Antarctica. We note that no correlation between PEL and AAO is identified prior to 1979 , which could be an artefact due to poor estimates of AAO before 1979, when few instrumental records were assimilated in atmospheric reanalyses.

The correlation coefficient of PEL temperature anomaly with the IPO index is weak (Fig. 4c), but the residuals of the PEL temperature regression with AAO are negatively correlated with the IPO index $(r=-0.47)$.

A multiple linear regression approach leads to the conclusion that combined variations in AAO and IPO explain 59\% of the temperature variance on an inter-annual scale. While such teleconnection between Pacific and central Antarctic climate have previously been reported from Vostok data (Ekaykin et al., 2014), the underlying mechanism is not known. Finally, no significant correlation was identified between PEL temperature and the IOD index (Fig. 4d).

However, different results emerge when considering the low-pass-filtered time series. On multi-decadal timescales, a strong positive correlation $(r=0.8$, significant with a 0.06 confidence level) relates PEL temperature and the AAO (Fig. 4a and b), and a very strong positive correlation appears between PEL temperature and the IOD index $(r=$ 0.93, $p<0.05)$. We suggest that the Indian Ocean Dipole affects the Antarctic climate through a modulation of cyclonic activity. This is indirectly confirmed by a negative correlation $(r=-0.56)$ between the IOD index and the pressure anomaly at Mirny and Davis (not shown). The positive relationship between AAO and temperature in the low-frequency band could then be an "induced correlation" caused by a very strong positive correlation between AAO and IOD $(r=0.8-$ $0.9)$ on these timescales. 


\subsection{Climatic variability in Princess Elizabeth Land over the last 350 years}

The stacked $\delta \mathrm{D}$ record (built from low-pass-filtered individual records) is now compared with the filtered PEL temperature composite (Fig. 4a). We observe a positive correlation with $r=0.66$. Although the length of the series is 52 years, the number of degrees of freedom is only 4 due to the 27 year filtering. The uncertainty of the correlation is \pm 0.4 , so it is statistically insignificant $(p=0.17)$.

This invokes a discussion of the factors that may disturb the correlation between the local air temperature and the stable water isotopic composition of precipitation in Antarctica (Jouzel et al., 2003).

Firstly, isotopic composition of precipitation is not a function of local air temperature but of the temperature difference between the evaporation area and the condensation site, which defines the degree of heavy water molecule distillation from an air mass. The study of the moisture origin for this sector of Antarctica (Sodemann and Stohl, 2009) demonstrates that different parts of the PEL differ in their moisture origin. Coastal areas receive moisture from higher latitudes $\left(46-52^{\circ} \mathrm{S}\right)$ and from more western longitudes $\left(0-40^{\circ} \mathrm{E}\right)$ than inland areas $\left(34-42^{\circ} \mathrm{S}\right.$ and $\left.40-90^{\circ} \mathrm{E}\right)$. It means that even if our sector is climatically uniform, as was shown above, the temporal variability of the precipitation isotopic content may differ in the different parts of the sector due to varying moisture origin.

Secondly, we should define which temperature is actually recorded in the isotopic composition of precipitation. For central Antarctica, where much (or most) of the precipitation is "diamond dust" from a clear sky (Ekaykin, 2003), the effective condensation temperature is conventionally considered equal to the temperature on the top of the inversion layer. But this is definitely not true for the coastal areas, where most precipitation falls from the clouds. Thus, the difference between near-surface and condensation temperature may vary in space and time.

Thirdly, the precipitation seasonality is another factor that may change the relationship between the air temperature and stable isotope content in precipitation. At Vostok the amount of precipitation is evenly distributed throughout the year (Ekaykin, 2003), so the snow isotopic content corresponds well to the mean annual air temperature, but we do not have robust information either about the other parts of the PEL or about the seasonality changes in the past.

Yet we believe that the main factor affecting the isotopetemperature relationship is "stratigraphic noise". Indeed, even when we study the ice cores obtained at a short distance from one another (Ekaykin et al., 2014), the correlation between the individual isotopic records is still small, though the climatic conditions are the same.

This is why we argue that constructing a stacked isotopic record is an optimal way to reduce the amount of noise in the series and to highlight the variability that is common for the whole studied region, provided that the region is climatically uniform.

Despite the statistically insignificant correlation coefficient, we assume that the stacked $\delta \mathrm{D}$ record is a proxy of surface air temperature in the PEL region (or following Steig et al., 2013, a proxy that "covaries with atmospheric circulation in a manner similar to temperature"). Thus, we estimate the calibration coefficient between these two parameters as a ratio of the standard deviation of the $\delta \mathrm{D}$ composite record to the standard deviation of the PEL low-passfiltered temperature record, which allows us to assign a temperature scale to the isotopic record. The apparent isotopetemperature gradient, obtained as a standard deviation of isotopic values divided by standard deviations of temperature values, is $13.8 \pm 2.5 \%{ }^{\circ} \mathrm{C}^{-1}$ (the uncertainty is due to different standard deviations of isotopic values in individual records). This approach implicitly suggests a perfect correlation between the compared series. If we correct the apparent slope by the observed correlation coefficient, 0.66 , it becomes $9 \pm 5.4 \%{ }^{\circ} \mathrm{C}^{-1}$. The latter value is still higher than the corresponding slopes observed in other regions of Antarctica (see a review in Stenni et al., 2016) but corresponds nicely to an isotope-condensation temperature slope predicted by a simple isotope model (Salamatin et al., 2004). Actually, low apparent isotope-temperature slopes obtained based on ice core data may be due to a significant amount of noise in the isotopic records, while in our case we removed the noise to a considerable extent by filtering and constructing the stacked record.

The temperature reconstruction is displayed in Fig. $5 \mathrm{~b}$ as a temperature anomaly relative to the 1980-2009 period. We also show the instrumentally obtained air temperature anomaly in Fig. $5 \mathrm{~b}$ on the same temperature scale.

Following Ekaykin et al. (2014), who reported a closer relationship between Vostok isotopic data and summer temperature than with the annual mean temperature, we performed additional analyses of relationships between our stacked isotope record and other temperature time series (e.g. monthly or seasonal temperature anomalies), but this does not improve the isotope-temperature correlation.

Despite discrepancies in the individual isotopic records (Fig. 3), a common signal identified in the stacked record leads to several conclusions about PEL climate variability over the past 350 years. During this time interval, regional surface air temperature shows a long-term increasing trend and an overall warming by about $1 \pm 0.6^{\circ} \mathrm{C}$. Superimposed on this multi-centennial trend, quasiperiodical variability occurs with periods of 30-40 and about 60 years. A colder period is identified in 1750-1860 - i.e. approximately at the same time interval as the Little Ice Age reported in other regions (PAGES 2k Consortium, 2013).

A remarkably cold phase is observed during the 1840 s, during which PEL temperature could fall $1.2 \pm 0.7^{\circ} \mathrm{C}$ below that of the present day (defined as the average value of the last 30 years). As seen in Fig. 3, this event is a robust feature, 


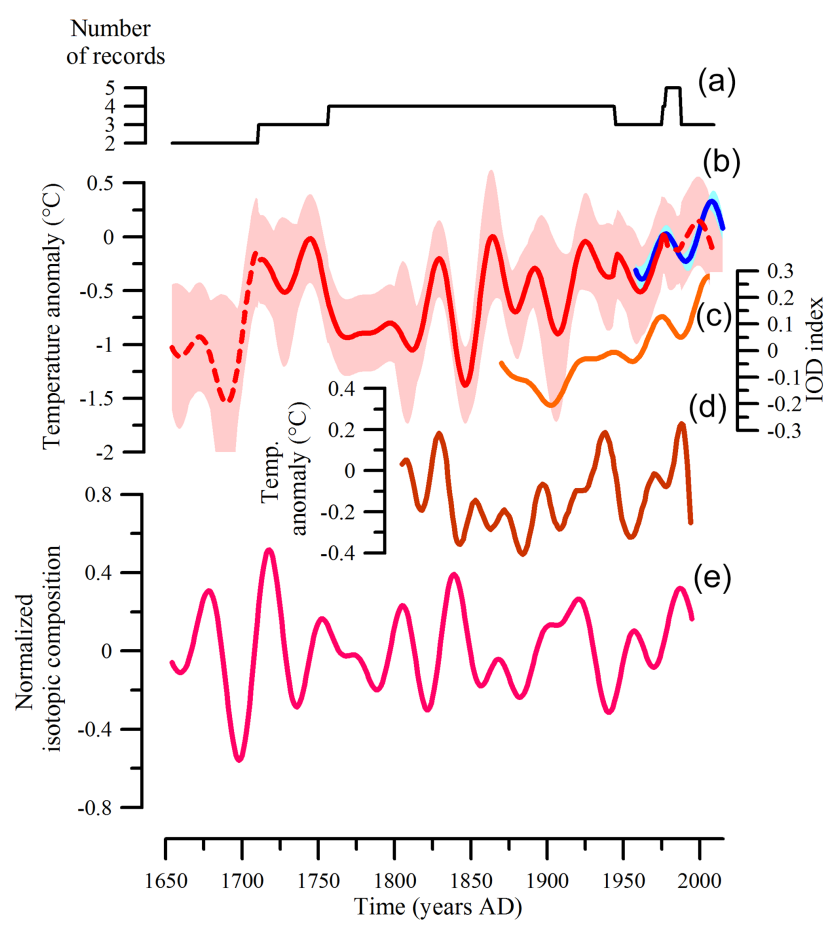

Figure 5. Antarctic climatic variability over the past 350 years. (a) Number of individual records in the stacked isotopic record; (b) temperature anomaly relative to 1980-2009, based on Princess Elizabeth Land meteorological records (blue) and reconstructed from the stacked isotopic record (PEL2016 - red). Shading is \pm 1 standard error of mean. Dashed lines denote less robust marginal parts of the PEL2016 record. (c) Low-pass-filtered values of the IOD index. (d) Antarctic temperature anomaly from Schneider et al. (2006). (e) Normalized and low-pass-filtered stacked isotopic record for East Antarctica (data from PAGES (Past Global Changes) 2k Consortium, 2013).

observed in all four individual records available for this time interval. This minimum was also identified in an Antarctic temperature stack record (Schneider et al., 2006) - see Fig. $5 \mathrm{~d}-$ as well as in an ice core drilled in the Ross Sea sector (Rhodes et al., 2012) and in the isotope record from Ferrigno (coastal Ellsworth Land) (Thomas et al., 2013).

Further studies are needed to understand whether such remarkably cold conditions arise from internal variability or are driven by the response of regional climate to an external perturbation. A possible candidate could be a response to volcanic forcing (Sigl et al., 2015). A moderate event is associated with the eruption of Cosiguiina in 1835. According to the inventory of volcanic events recorded in the Vostok firn cores (Osipov et al., 2014), an unknown volcano erupted in 1840; however, the amount of deposited sulfate was about $15 \%$ of that of Tambora, so it is not expected to have a major effect on the climate system. So far, the influence of volcanic forcing on Antarctic climate and the response time remain poorly known. By contrast, recent studies have stressed the delayed response of the North Atlantic Oscillation (Ortega et al., 2015) to major volcanic eruptions as well as their role as pacemakers of bidecadal variability in the North Atlantic (Swingedouw et al., 2015).

The period before 1700 is probably the coldest part of the record, but this is not a robust result as the two records spanning this time interval show somewhat different behaviours (Fig. 3). However, another stack of five East Antarctic cores from PAGES (Past Global Changes) 2k (Fig. 5e) also highlights that the 1690s could have been the coldest decade of the last 350 years. We also compare the PEL2016 record with other Antarctic temperature reconstructions. Schneider et al. (2006) used high-resolution isotopic records from five Antarctic sites (a stack of Law Dome records, Siple Station, a stack of Dronning Maud Land records and two ITASE (International Trans Antarctic Scientific Expedition) sites from West Antarctica). Although this record is not significantly correlated with PEL2016 $(r=0.36)$, we note some common features in both records (warming in the 1820s and 1890s, cold events in the 1840s and 1900s, etc.).

We also investigate the similarities between PEL2016 and the filtered stack normalized isotopic East Antarctic record based on five East Antarctic ice cores (Fig. 5e; data are available in the supplement of PAGES $2 \mathrm{k}$ Consortium, 2013). The correlation with PEL2016 is weak $(r=0.13)$ and insignificant, and so is the correlation with the stack from Schneider et al. (2006) $(r=0.36)$.

The main difference between our PEL2016 record and the other isotopic stacked records for the whole of Antarctica (Fig. 5d) and for East Antarctica (Fig. 5e) appears for long-term trends, with a long-term increase in PEL2016 but no similar feature in the other reconstructions. We suggest that contrasted regional long-term trends may disappear in continental-scale reconstructions (see Fig. S2).

Finally, we compare our PEL2016 record with an IOD time series since 1870 , also processed with a low-pass filter. The strong correlation coefficient $(r=0.79)$ confirms the close relationship between multi-decadal variations in surface air temperature in this sector of Antarctica and IOD. The Indian Ocean Dipole oscillation appears as the predominant climatic mode affecting multi-decadal climate variability in this part of East Antarctica. While the exact mechanisms underlying this relationship are not known, the IOD is expected to affect the inland Antarctic climate by modulating the cyclonic activity that brings heat and moisture to the Antarctic continent.

\subsection{Snow accumulation rate variability}

We now investigate the low-pass-filtered values of the snow accumulation rate, available at the $105 \mathrm{~km}, 200 \mathrm{~km}$ and Vostok sites (the latter is a stack curve from three deep snow pits), normalized over the period 1952-1981 (Fig. 6). All of them exhibit a negative trend, more prominent for the $200 \mathrm{~km}$ series. This result contradicts the stacked Antarctic snow accumulation rate record (Frezzotti et al., 2013) 


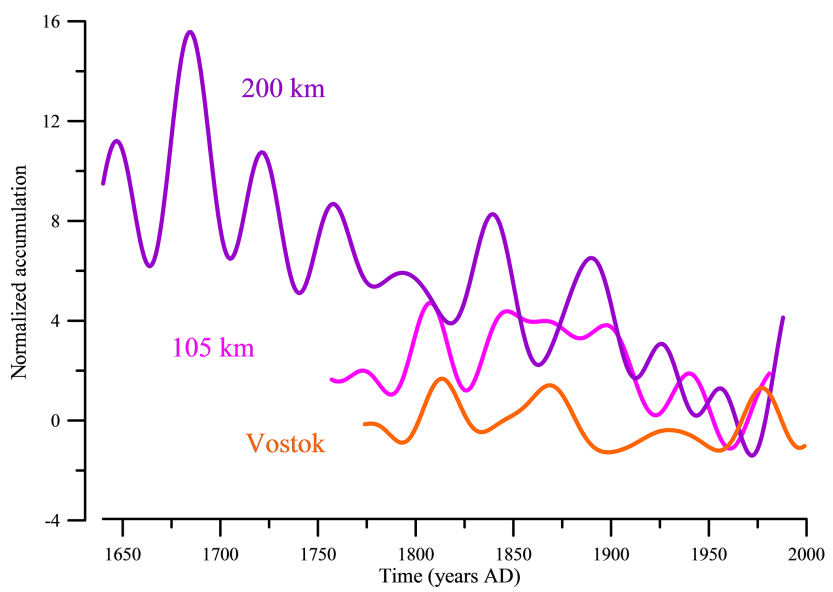

Figure 6. Normalized (relative to period 1952-1981) and low-passfiltered records of snow accumulation rate at sites $200 \mathrm{~km}$ (purple), $105 \mathrm{~km}$ (magenta) and Vostok (orange).

showing an overall increase in the accumulation rate during the last 200 years. Our finding is also not supported by the accurate assessment of average accumulation rate change between successive reference horizons at Vostok, showing a slight but significant increase in snow accumulation rate since 1816 (Ekaykin et al., 2004). Our results, moreover, stress the fact that, during the past few centuries, opposite long-term trends may have occurred in temperature and accumulation. This is counter-intuitive with respect to atmospheric thermodynamics and to the expected covariation of heat and moisture advection towards inland Antarctica. A similar divergence of the centennial trends of snow isotopic composition and accumulation rate was observed by Divine et al. (2009) at the coastal sites of Dronning Maud Land but not at the inland sites (Altnau et al., 2015).

Processes other than snowfall deposition may, however, affect the ice core records. In the vicinity of $105 \mathrm{~km}$, large "transversal" snow dunes have recently been evidenced (Vladimirova and Ekaykin, 2014). Such features may lead to a strong non-climatic variability in the snow accumulation rate at a given point, due to dune propagation effects. Blowing snow events may also have a significant influence on mass balance in the coastal zone of Antarctica (Scarchilli et al., 2010), potentially introducing additional post-deposition noise.

As a result, we are not confident that the datasets reported in Fig. 6 can be interpreted in terms of climate (snowfall) variations. Further work is needed to distinguish the large-scale climate effect (snowfall deposition) from the nonclimatic effects potentially associated with post-deposition (wind erosion, dune propagation, etc.).

\section{Conclusion}

In this paper, we presented an analysis of the recent variability in snow isotopic composition $(\delta \mathrm{D})$ data from six snow pits and ice cores recovered in the region of Princess Elizabeth Land (PEL), East Antarctica.

In order to interpret these data, we investigated the presentday mean annual surface air temperature variability using instrumental temperature measurements at the Mirny, Davis and Vostok stations, located at the margins of the sector being studied. It was shown that inter-annual climatic variability strongly covaries at these three stations. Cluster analysis demonstrated coherent variations for these stations, together with the nearby stations of Casey and Mawson. However, we stressed phase shifts between multi-decadal temperature variations along the coastal stations: temperature maxima and minima at Vostok and Mirny are delayed by a few years compared to those at Davis. On a broader geographical scale, temperature records from different sectors of Antarctica exhibit different climatic variability on a decadal scale in terms of periodicities, phasing and trends.

We then compared recent temperature variability in the PEL region with indices of Southern Hemisphere modes of variability and highlighted the importance of the Annular Antarctic Oscillation and the Interdecadal Pacific Oscillation, which in total explain $59 \%$ of the temperature variance in this Antarctic region. On the multi-decadal timescale, however, temperature variations appeared most closely related to the Indian Ocean Dipole mode, which may modulate the cyclonic activity that brings heat and moisture to Princess Elizabeth Land.

Given the limitations of ice core data for inter-annual variations, we processed our isotopic time series with a lowpass filter to cut off variability expressed on timescales $<27$ years. Both common features and significant discrepancies emerged from individual filtered time series. These differences may arise from true differences in regional climate variations and/or by non-climatic noise.

In order to improve the signal-to-noise ratio, we constructed a stacked isotopic record for the Princess Elizabeth Land based on data from all six sites. We then used the linear regression between this record and the instrumentally obtained air temperature record in order to convert the isotopic composition scale into an air temperature scale. The apparent isotope-temperature slope is $9 \pm 5.4 \% 0^{\circ} \mathrm{C}^{-1}$.

The newly obtained temperature reconstruction covers the period from 1654 to 2009. During this time, the temperature appears to have gradually increased by about $1 \pm 0.6^{\circ} \mathrm{C}$, from a relatively cold period observed from the mid-17th to mid-19th centuries. The coldest decade is identified in the $1840 \mathrm{~s}$, a feature common to several Antarctic isotopic composite signals. By contrast, long-term temperature trends were not identified previously in pan-Antarctic stacked records, possibly due to the averaging effects of different regional trends. We found a weak positive correlation 
of our temperature reconstruction with reconstructions previously obtained for the whole Antarctic continent and/or East Antarctica. A poor correlation between different Antarctic temperature records based on ice core data from different (but partly overlapping) regions requires further improvements to ice-core-based climate reconstructions.

Finally, our PEL record appeared closely related to the low-frequency component of the Indian Ocean Dipole mode.

The three accumulation time series depicted decreasing long-term trends and large inter-site differences. Further investigations of non-climatic drivers (including wind erosion and dune effects) are needed prior to confident climatic interpretation.

Our time series is provided as a Supplement to this manuscript. Understanding the cause of the reconstructed changes will require us to compare the PEL record with other regional Antarctic records, expanding the work of Jones et al. (2016) and combining simulations and reconstructions in order to better understand the mechanisms of regional climate multi-decadal to centennial variations and to explore the potential response of Antarctic climate to external forcing factors (e.g. volcanic eruptions).

Finally, this study stresses the importance of obtaining a dense network of highly resolved ice core records in order to document the complexity of spatio-temporal variations in the Antarctic climate, a key focus of the Antarctic $2 \mathrm{k}$ project (http://www.pages-igbp.org/ini/wg/antarctica2k/intro).

\section{Data availability}

Data to this article can be found in the Supplement.

\section{The Supplement related to this article is available online at doi:10.5194/cp-13-61-2017-supplement.}

Competing interests. The authors declare that they have no conflict of interest.

Acknowledgement. We kindly thank Barbara Stenni (the editor of the paper), Elisabeth Thomas, Dmitriy Divine (the reviewers) and Thomas Laepple, whose valuable comments and corrections allowed us to significantly improve the manuscript. We are very grateful to Alice Lagnado for improving the English.

This work is a contribution to the PAGES and IPICS "Antarctica $2 k$ " projects. We are grateful to all the field technicians of the Russian Antarctic Expedition (RAE) and the drillers from St Petersburg Mining University for providing us with high-quality ice cores. We thank RAE for logistical support of our work in Antarctica. The Russian-French collaboration in the field of ice cores and paleoclimate studies is carried out in the framework of the International Associated Laboratory "Vostok". We thank the CERL's staff for the isotopic analyses. The chemical analyses of the samples were performed at Irkutsk's Limnological Institute of RAS in the framework of the Russian Foundation for Basic Research grant 15-55-16001. One of the authors (Valérie Masson-Delmotte) was supported by Agence Nationale de la Recherche in France, grant ANR-14-CE010001 .

This study was completed with financial support from the Russian Science Foundation, grant 14-27-00030.

Edited by: B. Stenni

Reviewed by: D. Divine and E. Thomas

\section{References}

Altnau, S., Schlosser, E., Isaksson, E., and Divine, D.: Climatic signals from 76 shallow firn cores in Dronning Maud Land, East Antarctica, The Cryosphere, 9, 925-944, doi:10.5194/tc-9-9252015, 2015.

Carril, A. F. and Navarra, A.: Low-frequency varibility of the Antarctic Circumpolar Wave, Geophys. Res. Lett., 28, 46234626, 2001.

Divine, D. V., Isaksson, E., Kaczmarska, M., Godtliebsen, F., Oerter, H., Schlosser, E., Johnsen, S. J., van den Broeke, M., and van de Wal, R. S. W.: Tropical Pacific - high latitude south Atlantic teleconnections as seen in $\delta^{18} \mathrm{O}$ variability in Antarctic coastal ice cores, J. Geophys. Res., 114, D11112, doi:10.1029/2008JD010475, 2009.

Dong, B. and Dai, A.: The influence of the Interdecadal Pacific Oscillation on temperature and precipitation over the globe, Clim. Dynam., 15, 2667, doi:10.1007/s00382-015-2500-x, 2015.

Ekaykin, A. A.: Meteorological regime of central antarctica and its role in the formation of isotope composition of snow thickness, Universite Joseph Fourier, Grenoble, 136 pp., 2003.

Ekaykin, A. A., Lipenkov, V. Y., Barkov, N. I., Petit, J. R., and Stievenard, M.: The snow accumulation variability over the last 350 years at the slope of Antarctic ice sheet at $200 \mathrm{~km}$ from the Mirny observatory, Kriosfera Zemli, 4, 57-66, 2000 (in Russian).

Ekaykin, A. A., Lipenkov, V. Y., Kuzmina, I. N., Petit, J. R., Masson-Delmotte, V., and Johnsen, S.: The changes in isotope composition and accumulation of snow at Vostok station over the past 200 years, Ann. Glaciol., 39, 569-575, 2004.

Ekaykin, A. A., Kozachek, A. V., Lipenkov, V. Y., and Shibaev, Y. A.: Multiple climate shifts in the Southern Hemisphere over the past three centuries based on central Antarctic snow pits and core studies, Ann. Glaciol., 55, 259-266, 2014.

EPICA: Eight glacial cycles from an Antarctic ice core, Nature, 429, 623-628, doi:10.1038/nature02599, 2004.

Frezzotti, M., Scarchilli, C., Becagli, S., Proposito, M., and Urbini, S.: A synthesis of the Antarctic surface mass balance during the last 800 yr, The Cryosphere, 7, 303-319, doi:10.5194/tc-7-3032013, 2013.

Giese, B. S., Urizar, S. C., and Fuckar, N. S.: Southern hemisphere origins of the 1976 climate shift, Geophys. Res. Lett., 29, 1-4, 2002.

Henley, B. J., Gergis, J., Karoly, D. J., Power, S., Kennedy, J., and Folland, C. K.: A tripole index for the Interdecadal Pacific Oscillation, Clim. Dynam., 15, 3077, doi:10.1007/s00382-015-2525$1,2015$. 
Jones, J. M., Gille, S. T., Goosse, H., Abram, N. J., Canziani, P. O., Charman, D. J., Clem, K. R., Crosta, X., de Lavergne, C., Eisenman, I., England, M. H., Fogt, R. L., Frankcombe, L. M., Marshall, G. J., Masson-Delmotte, V., Morrison, A. K., Orsi, A. J., Raphael, M. N., Renwick, J. A., Schneider, D. P., Simpkins, G. R., Steig, E. J., Stenni, B., Swingedouw, D., and Vance, T. R.: Assessing recent trends in high-latitude Southern Hemisphere surface climate, Nature Climate Change, 6, 917-926, doi:10.1038/nclimate3103, 2016.

Jouzel, J., Vimeux, F., Caillon, N., Delaygue, G., Hoffmann, G., Masson-Delmotte, V., and Parrenin, F.: Magnitude of isotope/temperature scaling for interpritation of central antarctic ice cores, J. Geophys. Res., 108, 1-10, 2003.

Kaspari, S., Mayewski, P. A., Dixon, D. A., Spikes, V. B., Sneed, S. B., Handley, M. J., and Hamilton, G. S.: Climate variability in West Antarctica derived from annual accumulatiuon-rate records from ITASE firn/ice cores, Ann. Glaciol., 39, 585-594, 2004.

Lipenkov, V. Y., Ekaykin, A. A., Barkov, N. I., and Pourchet, M.: On the relation of surface snow density in Antarctica to wind speed, Materialy Glyatsiologicheskih Issledovaniy, 85, 148-158, 1998 (in Russian).

Marshall, G. J.: Trends in the Southern Annular Mode from observations and reanalysis, J. Climate, 16, 4134-4143, 2003.

Masson-Delmotte, V., Hou, S., Ekaykin, A. A., Jouzel, J., Aristarain, A., Bernardo, R. T., Bromwich, D., Cattani, O., Delmotte, M., Falourd, S., Frezzotti, M., Gallee, H., Genoni, L., Isaksson, E., Landais, A., Helsen, M., Hoffmann, G., Lopez, J., Morgan, V., Motoyama, H., Noone, D., Oerter, H., Petit, J. R., Royer, A., Uemura, R., Schmidt, G. A., Schlosser, E., Simoes, J. C., Steig, E., Stenni, B., Stievenard, M., van den Broeke, M., van de Wal, R., van den Berg, W.-J., Vimeux, F., and White, J. W. C.: A review of Antarctic surface snow isotopic composition: Observations, atmospheric circulation and isotopic modelling, J. Climate, 21, 3359-3387, 2008.

Oerter, H., Wilnelms, F., Jung-Rothenhausler, F., Goktas, F., Miller, H., Graf, W., and Sommer, S.: Accumulation rates in Dronning Maud Land, Antarctica, as revealed by dielectric-profiling measurements of shallow firn cores, Ann. Glaciol., 30, 27-34, 2000.

Ortega, P., Lehner, F., Swingedouw, D., Masson-Delmotte, V., Raible, C. C., Casado, M., and Yiou, P.: A model-tested North Atlantic Oscillation reconstruction for the past millennium, Nature, 523, 71-77, doi:10.1038/nature14518, 2015.

Osipov, E. Y., Khodzher, T. V., Golobokova, L. P., Onischuk, N. A., Lipenkov, V. Y., Ekaykin, A. A., Shibaev, Y. A., and Osipova, O. P.: High-resolution 900 year volcanic and climatic record from the Vostok area, East Antarctica, The Cryosphere, 8, 843-851, doi:10.5194/tc-8-843-2014, 2014.

PAGES 2k Consortium: Continental-scale temperature variability during the past two millennia, Nat. Geosci., 6, 339-346, doi:10.1038/ngeo1797, 2013.

Paillard, D., Labeyrie, L., and Yiou, P.: Macintosh program performs time-series analysis, EOS T. Am. Geophys. Un., 77, p. 379, 1996.

Rhodes, R. H., Bertler, N. A. N., Baker, J. A., Steen-Larsen, H. C., Sneed, S. B., Morgenstern, U., and Johnsen, S. J.: Little Ice Age climate and oceanic conditions of the Ross Sea, Antarctica from a coastal ice core record, Clim. Past, 8, 1223-1238, doi:10.5194/cp-8-1223-2012, 2012.
Salamatin, A. N., Ekaykin, A. A., and Lipenkov, V. Y.: Modelling isotopic composition in precipitation in central antarctica, Materialy Glyatsiologicheskih Issledovaniy, 97, 24-34, 2004.

Scarchilli, C., Frezzotti, M. P. G., De Silvestri, L., Agnoletto, L., and Dolci, S.: Extraordinary blowing snow transport events in East Antarctica, Clim. Dynam., 34, 1195-1206, doi:10.1007/s00382009-0601-0, 2010.

Schneider, D. P., Steig, E., Van Ommen, T., Dixon, D. A., Mayewski, P. A., Jones, J. M., and Bitz, C. M.: Antarctic temperatures over the past two centuries from ice cores, Geophys. Res. Lett., 33, 1-5, 2006.

Sigl, M., Winstrup, M., McConnell, J. R., Welten, K. C., Plunkett, G., Ludlow, F., Buntgen, U., Caffee, M., Chellman, N., Dahl-Jensen, D., Fischer, H., Kipfstuhl, S., Kostick, C., Maselli, O. J., Mekhaldi, F., Mulvaney, R., Muscheler, R., Pasteris, D. R., Pilcher, J. R., Salzer, M., Schupbach, S., Steffensen, J. P., Vinther, B. M., and Woodruff, T. E.: Timing and climate forcing of volcanic eruption for the past 2,500 years, Nature, 253, 543-549, doi:10.1038/nature14565, 2015.

Sodemann, H. and Stohl, A.: Asymmetries in the moisture origin of Antarctic precipitation, Geophys. Res. Lett., 36, L22803, doi:10.1029/2009GL040242, 2009.

Steig, E., Ding, Q., White, J. W. C., Kuttel, M., Rupper, S. B., Neumann, T. A., Neff, P. D., Gallant, A. J. E., Mayewski, P. A., Taylor, K. C., Hoffmann, G., Dixon, D. A., Schoenemann, S. W., Markle, B. R., Fudge, T. J., Schneider, D. P., Schauer, A. J., Teel, R. P., Vaughn, B. H., Burgener, L., Williams, J., and Korotkikh, E.: Recent climate and ice-sheet changes in West Antarctica compared with the past 2,000 years, Nat. Geosci., 6, 372375, 2013.

Stenni, B., Scarchilli, C., Masson-Delmotte, V., Schlosser, E., Ciardini, V., Dreossi, G., Grigioni, P., Bonazza, M., Cagnati, A., Karlicek, D., Risi, C., Udisti, R., and Valt, M.: Three-year monitoring of stable isotopes of precipitation at Concordia Station, East Antarctica, The Cryosphere, 10, 2415-2428, doi:10.5194/tc-102415-2016, 2016.

Swingedouw, D., Ortega, P., Mignott, J., Guilyardi, E., MassonDelmotte, V., Butler, P. G., Khodri, M., and Seferian, R.: Bidecadal north Atlantic ocean circulation variability controlled by timing of volcanic eruptions, Nat. Commun., 6, 1-12, doi:10.1038/ncomms7545, 2015.

Thomas, E. R., Bracegirdle, T. J., Turner, J., and Wolff, E. W.: A 308 year record of climate variability in West Antarctica, Geophys. Res. Lett., 40, 5492-5496, doi:10.1002/2013GL057782, 2013.

Turner, J., Colwell, S. R., Marshall, G. J., Lachlan-Cope, T. A., Carleton, A. M., Jones, P. D., Lagun, V., Reid, P. A., and Iagovkina, S.: The SCAR READER project: Toward a high-quality database of mean Antarctic meteorological observations, J. Climate, 17, 2890-2898, doi:10.1175/15200442(2004)017<2890:TSRPTA>2.0.CO;2, 2004.

Vladimirova, D. O. and Ekaykin, A. A.: Climatic variability in Davis Sea sector (East Antarctica) for the last 250 years based on geochemical investigations of " $105 \mathrm{~km}$ " ice core, Probl. Arktiki i Antarktiki, 1, 102-113, 2014 (in Russian).

Vladimirova, D. O., Ekaykin, A. A., Lipenkov, V. Y., Popov, S. V., Petit, J.-R., and Masson-Delmotte, V.: A synthesis of groundbased data of surface snow isotopic composition and accumulation rate in Princess Elisabeth Land, East Antarctica, in preparation, 2017. 